\title{
Cooling System Expansion Tank Safety Note
}

G. S. Ball

\author{
$01 / 27 / 89$
}

D-Zero Engineering Note \#3740.510.EN-204

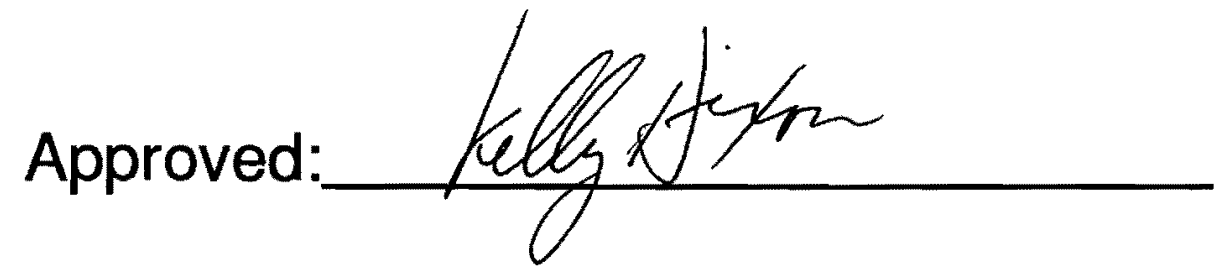


PRESSURE VESSEL ENGINEERING NOTE

PER MANDATORY STANDARD SD37

\begin{tabular}{l} 
Prepared by: Greg Ball $4802 \quad M S-357$ \\
Preparation date: January 12,1989 \\
\hline
\end{tabular}

1 Description and Identification

Fill in the label information below:

This vessel conforms to engineering standard SD37

Vesse1 Title Cooling System Receiving Tank

Vesse1 Number RD $4003 \quad N B-5 / 61$

Vesse1 Drawing Number

Maximum Allowable

Working Pressure (MAWP)

Working Temperature Range $\begin{array}{lllll} & -20 & { }^{\circ} \mathrm{F} & 450 & { }^{\circ} \mathrm{F}\end{array}$

Contents $50 \%$ Glycol $50 \%$ water

Designer/Manufacturer Silvan Industries. Inc.

Test Pressure (if tested at Fermi) $\begin{aligned} & \text { Acceptance } \\ & \text { Date: }\end{aligned}$

PSI, Hydraulic

Pneumatic

Accepted as conforming, to standard by

1L.C.7etranfines

of Division/Section Research Air.

NOTE: Any subsequent changes in contents, pressures, temperatures, valving, etc., which affect the safety of this vessel shall require another review and test.

Reviewed by: Dused Q. Pucins:

Date: Stanumy 19,1989

Director's signature (or designee) if the vessel is for manned areas but doesn't conform to the requirements of the standard.

Date:

Lab Property Number(s):

Lab Location Code: DAB-AH (obtain from Safety Officer)

Purpose of Vesse1(s): Supplies positive pressure to pump and separates air bubbles in pump cooling system and protects against pressure surges

Vesse1 Capacity/Size: $10 \mathrm{gal}$ Diameter : 12 " Length: 22 "

Normal Operating Pressure (OP) PSI

MAWP-OP = PSI

Is the above enough to provide relief cracking pressure tolerance plus system uncertainty tolerance per $M-9$.

As an option, provide a photo of the entire vessel in the Appendix. 
PRESSURE VESSEL ENGINEERING NOTE

PER MANDATORY STANDARD SD 37

Prepared by: Greg Ball

Preparation date: January 12, 1989

1 Description and Identification

Fill in the label information below:

This vesse1 conforms to engineering standard SD37

Vessel Title Cooling System Receiving Tank

Vessel Number_ RD 4003

Vesse1 Drawing Number

Obtain from

Maximum Allowable

Working Pressure (MAWP)

200

PSI

Working Temperature Range $\quad-20 \quad{ }^{\circ} \mathrm{F} \quad 450 \quad{ }^{\circ} \mathrm{F}$

Contents $50 \%$ Glycel $50 \%$ water

Designer/Manufacturer_silvan Industries, Inc.

Test Pressure (if tested at Fermi) Acceptance
Date: PSI, Hydraulic

Pneumatic

Accepted as conforming to standard by

\section{of Division/Section}

NOTE: Any subsequent changes in contents, pressures, temperatures, valving, etc., which affect the safety of this vessel shall require another review and test.

Reviewed by:

Date:

Director's signature (or designee) if the vessel is for manned areas but doesn't conform to the requirements of the standard.

Date:

Lab Property Number(s):

Lab Location Code: DAB-AH (obtain from Safety officer)

Purpose of Vessel(s): Supplies positive pressure to pump and separates air bubbles in pump cooling system and protects against pressure surges

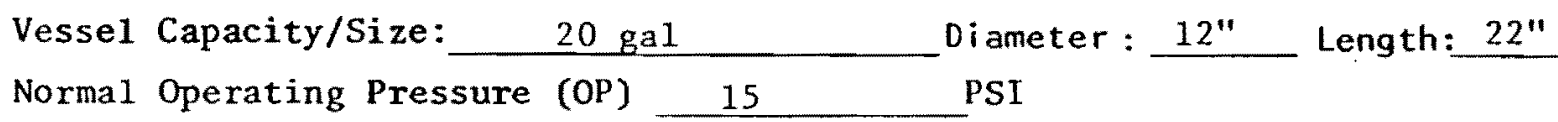

MAWP-OP $=185 \quad$ PSI

Is the above enough to provide relief cracking pressure tolerance plus system uncertainty tolerance per $\mathrm{M}-9$.

As an option, provide a photo of the entire vessel in the Appendix. 
List the numbers of all pertinent drawings and the location of the originals. (Append copies).

Drawing \#

See sketch in appendix

\section{Design Verification}

Does the vessel (s) have a $U$ stamp? Yes $X$ No___. If "Yes", fill out data below and skip page 3 ; if "No", fill out page 3 and skip this page.

Staple photo of $U$ stamp plate below.

Copy "U" label details to the side if photo is not clear of if copies are unreadable.

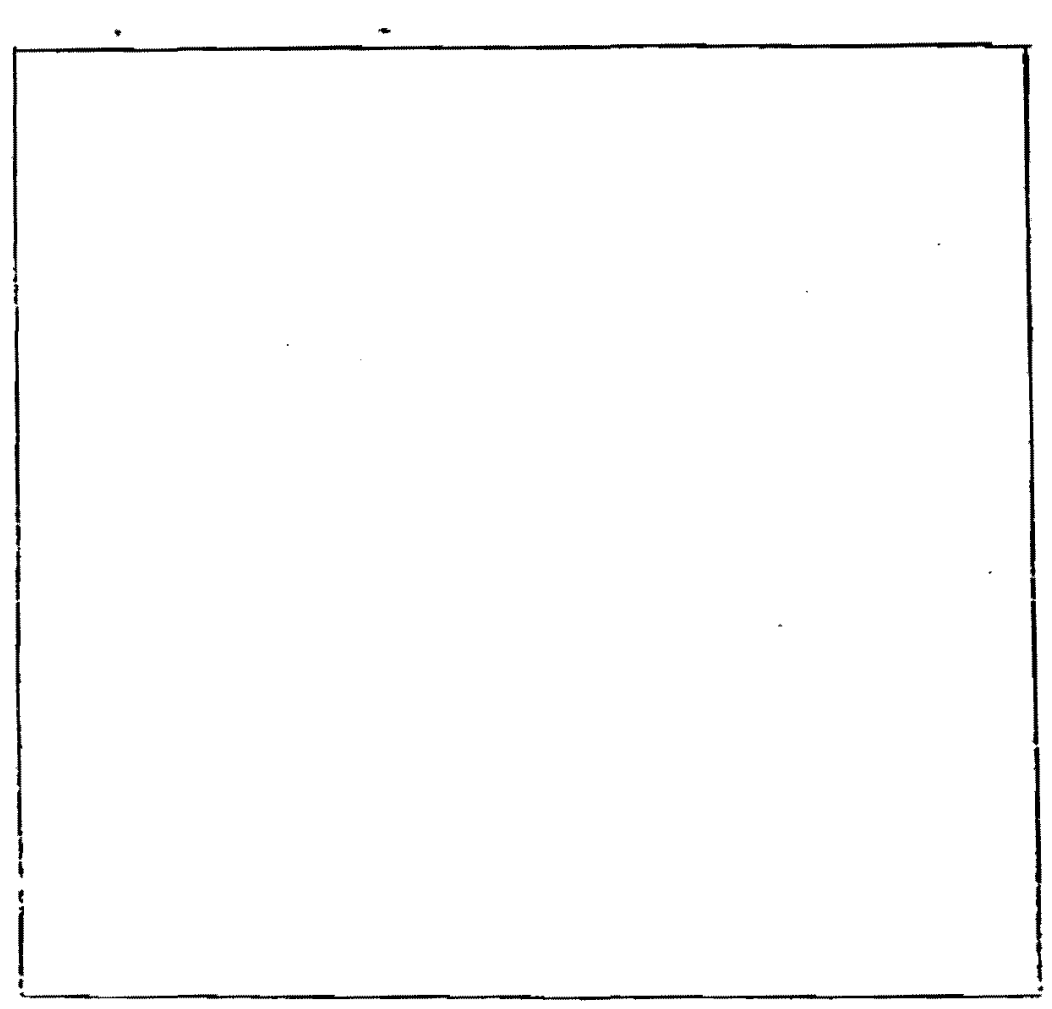

Location of Origina1 
On the sketch below, circle all applicable sections of the ASME code per Section VIII, Division I. List the results of all calculations. (Insert copies of calculations in the appendix).

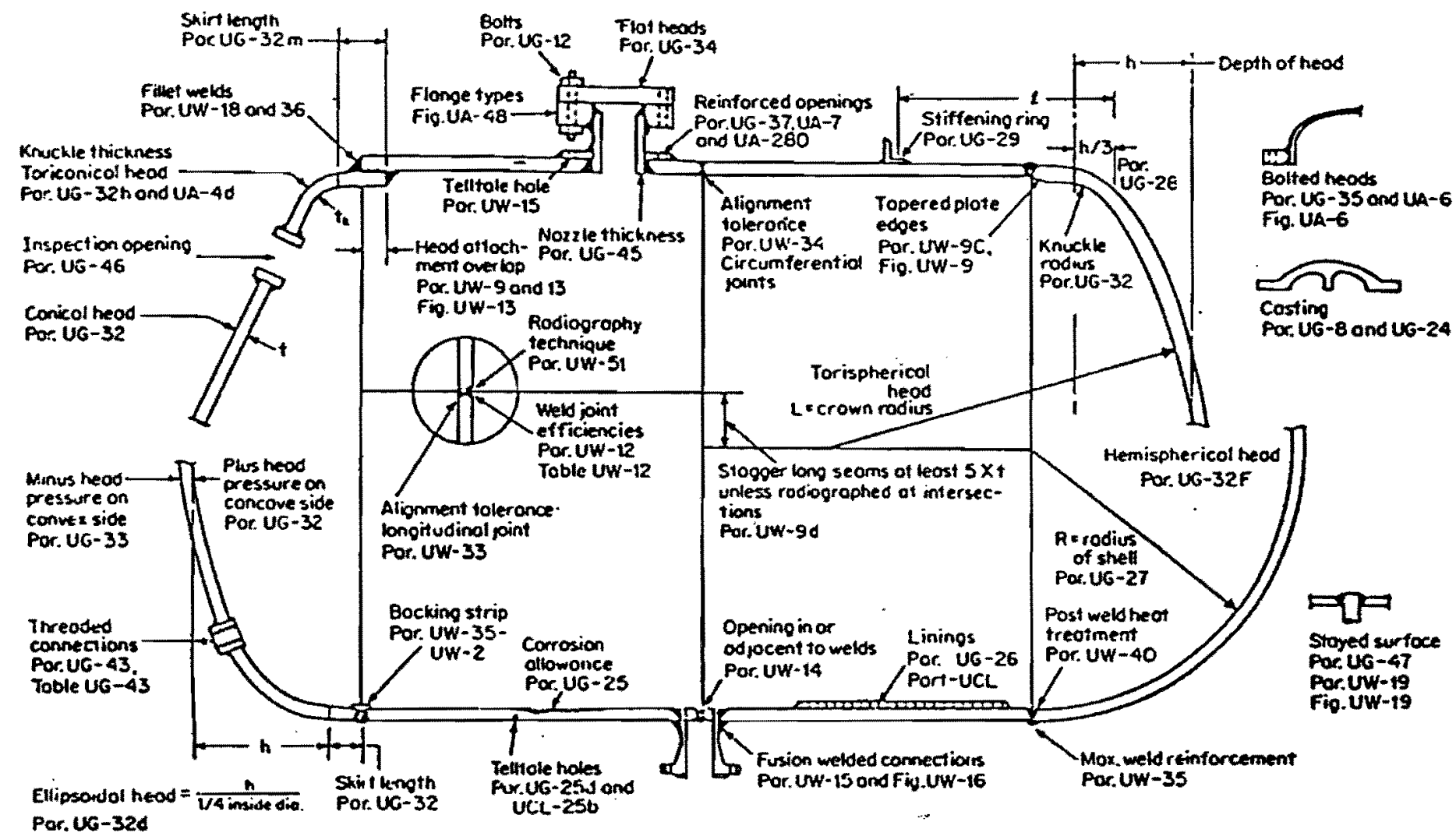

Summary of ASME Code

CALCULATION RESULT

(Required thickness or stress level vs. actual thickness or calculated stress level)

vs.

vs.

Vs.

VS.

vs.

If this vessel is exceptional or had exceptional parts, list their details under 5.6. Yes No 
3 System Venting. Provide the system schematic in the Appendix, if the vesse1 safety is system sensitive.

Is it possible to isolate the relief valves by a valve from the vessel?

Yes No $\mathrm{X}$

If "Yes", the system must conform to M-5. Provide an explanation on the appended schematic. (An isolatable vessel, not conforming to M-5 violates the Standard.)

Is the relief cracking pressure set at or below the M.A.W.P.?

Yes $X$ No_ Actual setting 25 PSI

(A no response violates the Standard.)

Is the pressure drop of the relief system at maximum anticipated flow such

that vessel pressure never rises above the following? (UG 125)

Yes $x$ No

$110 \%$ of MAWP (one relief)

$116 \%$ of MAWP (multiple reliefs)

$121 \%$ of MAWP (unexpected heat source)

Provide test or calculational proof in the Appendix.

(Non-conforming pressure rises violate the Standard.)

List of reliefs and settings:

Manufacturer $\quad \underline{\text { Relief Setting Flow Rate }}$

Kunkle Valve Co. $\quad$ Valve $25 \mathrm{psi} 358 \mathrm{~b} / \mathrm{hr} \quad 3 / 4$ inch

Is the relief device an ASME stamped device? Yes $\mathrm{X}$ No

4 Operating Procedure

Is an operating procedure necessary for the safe operation of this vessel?

Yes_ No_ $X$ _ If "Yes", please append.

5 Welding Information

Has the vessel been fabricated in a Fermilab shop? Yes ___ No $\mathrm{X}$

If "Yes", append a copy of the welding shop statement of welder qualification

and a copy of the Welding Procedure Specification (WPS) used to weld this vessel.

6 Exceptional, Existing, Used, and Non-Manned Area Vessels

Is this vessel or any part thereof in the above categories? Yes__ No $X$

If "Yes", follow the Engineering Note requirements for documentation in free form below. 
G. B a 1

$1 / 12 / 89$

From pump curves, pump can't produce $>85 \mathrm{ft}$. head

$$
\begin{aligned}
h= & \frac{\Delta p g_{c}}{p g} \\
& \frac{h p g}{g c}=\Delta p
\end{aligned}
$$

$\mathrm{h}=85 \mathrm{ft}$.

$\mathrm{p}=62.4 \frac{\mathrm{lbm}}{\mathrm{ft}^{3}} \quad$ (assume $\simeq{ }_{\mathrm{H}} \mathrm{p}_{2}$ )

$g=32.2 \mathrm{ft} / \mathrm{s}^{2}$

$\mathrm{g}_{\mathrm{C}}=32.21 \mathrm{bm}-\mathrm{ft} / 1 \mathrm{~b}_{\mathrm{f}}-\mathrm{s}^{2}$

$\Delta p=5304 \quad 1 b_{f} / f t=\langle 37$ psi

Initial tank pressure $=\mathrm{p}_{\mathrm{atm}}$

$p_{\text {atm }}+37$ psi $<200$ psi 


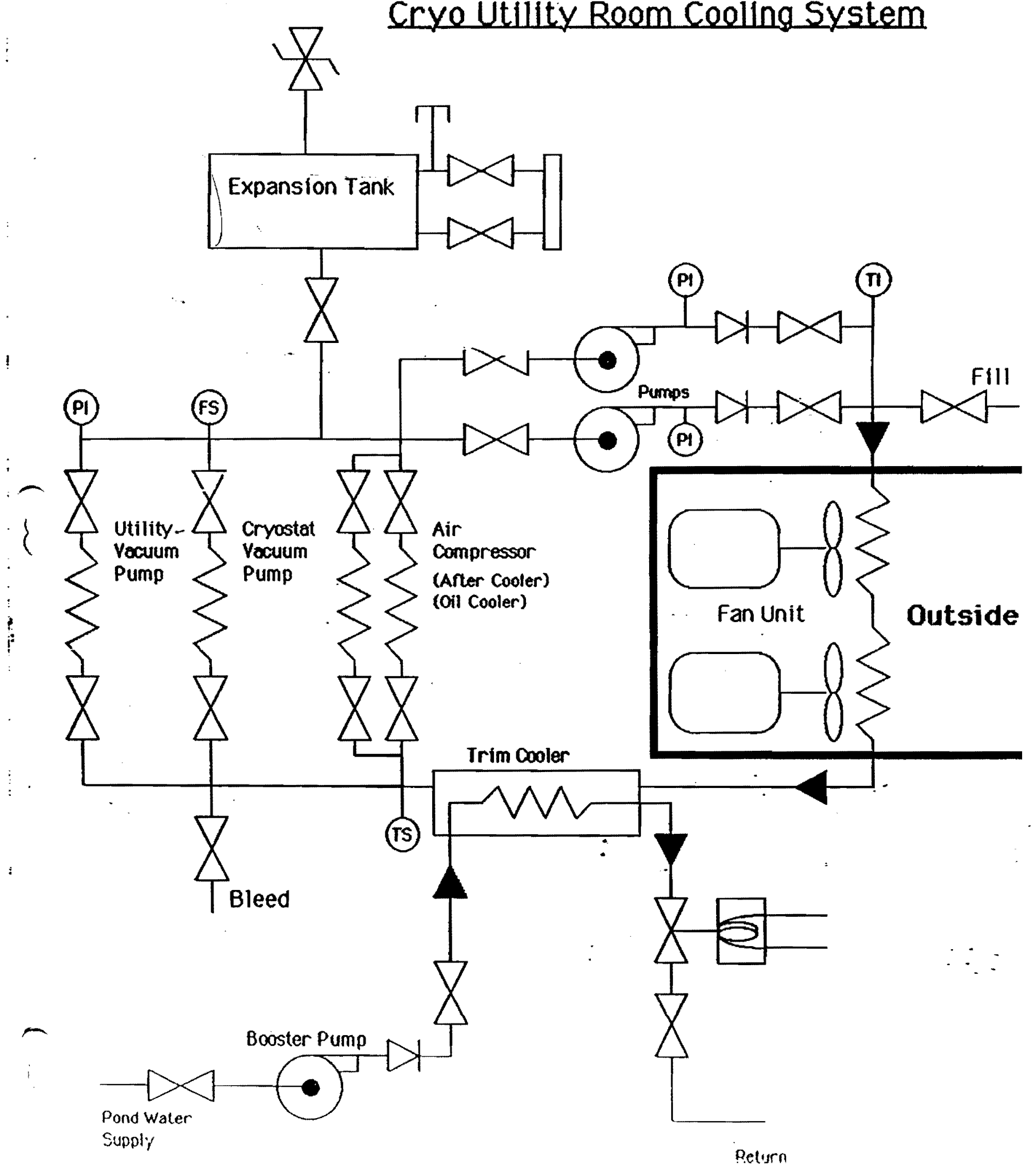




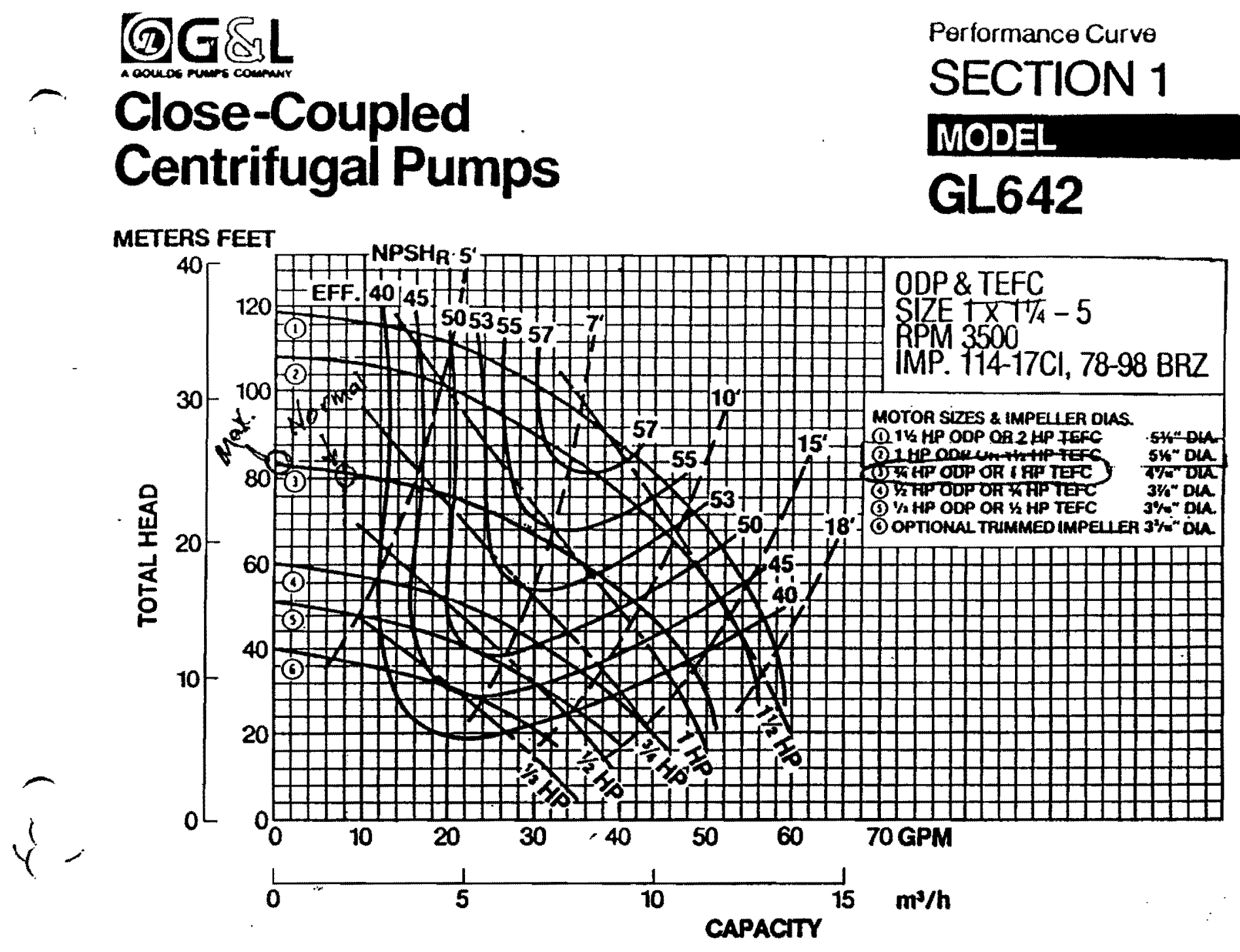



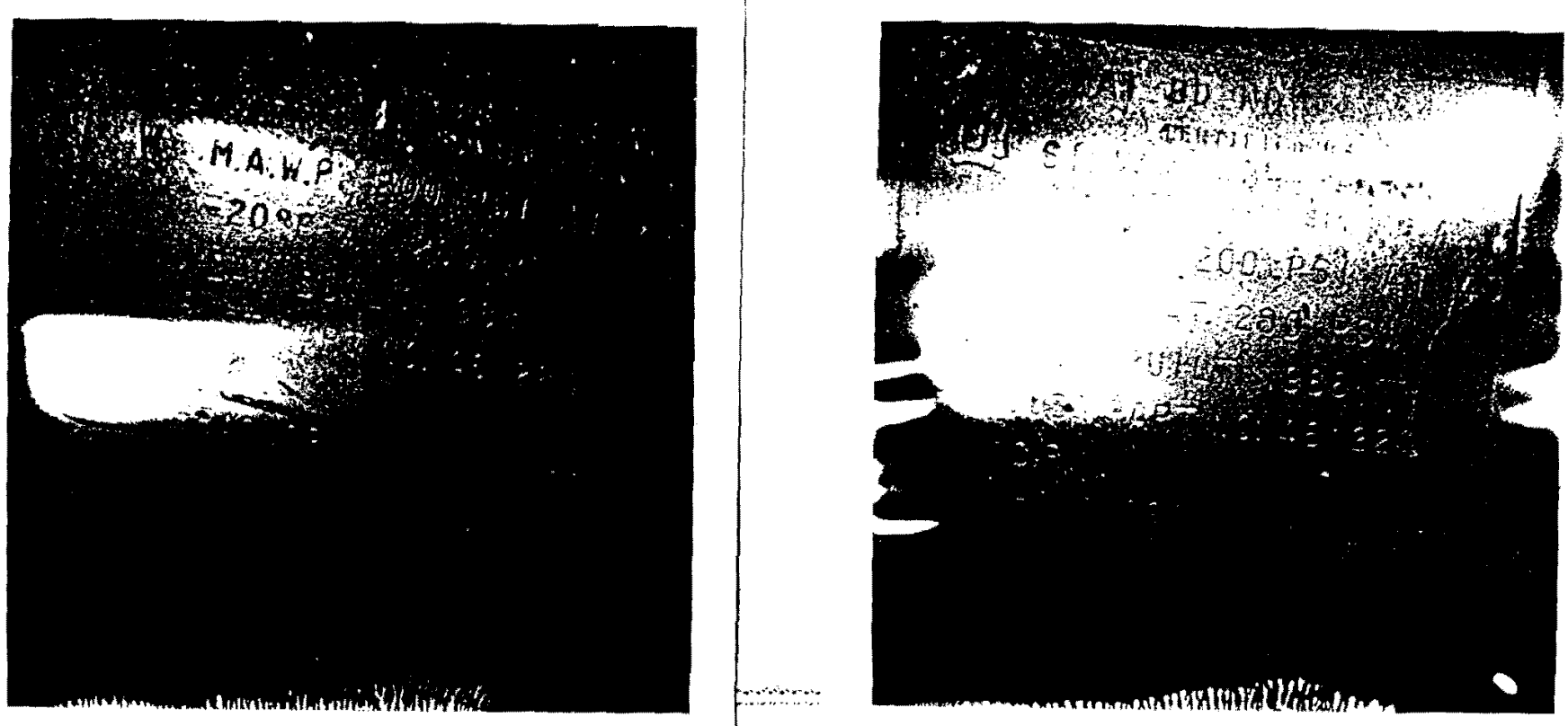